\title{
Tipologia morfossintática da negação nas línguas do tronco Tupi
}

\begin{abstract}
The aim of this study is to describe the different kinds of functions of negation according to the syntactical context they occur in: declarative, existential, and prohibitive sentences, in the negation of nominalized predicates, as well as in the negation of constituents. These negative functions are analized typologically with regard to the number of functions occurring in the different languages and with regard to morphological cohesion. Negation may be expressed by synthetical morphology (suffixes, discontinuous morphemes) or by syntagmatic constructions (analytical morphology: particles and auxiliaries). As a result, Tupi-Guarani languages show more morphological cohesion than members of the other Tupi families.

Keywords: Negation; Declarative; Lexical, Prohibitive; Typology; Synthetical; Analytical.

RESUMO: Neste estudo se descrevem, em boa parte das línguas do tronco tupi, com a inclusão da família Tupi-Guarani, as diferentes funções de negação nas orações declarativas e existenciais, nos predicados nominalizados, nas proibitivas e na negação de constituintes. Analisam-se estas funções de negação numa tipologia que considera o número de funções negativas e numa segunda tipologia que se estabelece com respeito à coesão morfológica das expressões negativas. Essa pode ser maior (morfologia sintética) ou menor (morfologia analítica). Resulta que as línguas Tupi-Guarani, na sua maioria, desenvolveram um maior grau de síntese do que membros das outras famílias Tupi.
\end{abstract}

Palavras-chave: Negação; Declarativa; Lexemática; Proibitiva; Tipologia; Sintético; Analítico.

\section{Introdução}

O objetivo deste artigo é apresentar uma análise tipológica das diferentes formas da negação nas línguas de todas as ramas do tronco Tupi, inclusive as da família TupiGuarani. A análise baseia-se na minha documentação das estratégias e formas da negação em 40 línguas aproximadamente.

\subsection{As classes de negações}

Nem todas as línguas Tupi estão descritas suficientemente. Os artigos especializados são raros e até as melhores gramáticas recentes se caracterizam por descuidos em certos tipos de negação. Depois de meu primeiro trabalho (Dietrich 2003), o número das descrições linguísticas aumentou consideravelmente, tanto no tronco Tupi, como em outras famílias (cf. Michael \& Granadillo 2014). 
DIETRICH - TIPOLOGIA MORFOSSINTÁTICA DA NEGAÇÃO NAS LÍNGUAS DO ...

As distinções fundamentais da negação nas línguas do tronco Tupi são as seguintes:

\section{Negação}
1) declarativa
2) nominalizadora
3) proibitiva
4) pronomes indefinidos
1a) de cláusula
2a) antonímica vs. privativa negativos
1b) existencial
2b) sem distinção
5) livres
1c) de constituintes

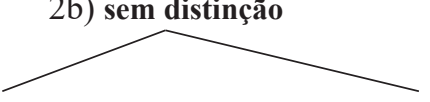
2b1) lexemática
2b2) subordinadas adverbiais

Não consideramos aqui as negações livres, sintaticamente equivalentes a orações, que se desenvolveram em algumas línguas (p. ex. guar. parag. hẽe - nahániri 'sim - não'; kagwahiva ha 'ã - ahan 'sim - não'; gavião aáv 'sim', surui-paiter tay 'no'). Também não consideramos os pronomes indefinidos negativos correspondentes a 'ninguém', 'nada'.

Opõem-se no centro as declarativas e as proibitivas. As declarativas subdividem-se em negações de cláusula existentes em todas as línguas analisadas, as existenciais e as de constituintes focalizados, funções que se encontram só em algumas das línguas. Num segundo nível, todas as negações mencionadas - as declarativas e as proibitivas - se opõem às negações lexemáticas. Estas, em geral, são formas predicativas nominalizadas, nas quais a negação funciona como nominalizador negativo. As negações lexemáticas podem formar subordinadas adverbiais de diferentes classes. Algumas negações lexemáticas podem, além disso, subdividir-se em formações antonímicas e privativas.

Com respeito às formas, há sufixos, morfemas descontínuos, posposições e partículas, derivadas de construções existenciais negativas. Estas transformaram-se em morfemas negativos que precedem as cláusulas que negam.

\subsection{A tipologia}

A tipologia é a disciplina da caracterização de estruturas linguísticas escolhidas pelo linguista. No caso da negação se recomenda a tipologia das estratégias morfossintáticas que funcionam em uma língua ou nas línguas que se comparam. Desta disciplina resulta a vantagem de poder abranger, em um grande número de línguas, as estratégias privilegiadas em umas e outras línguas. Para o campo da negação veja-se Miestamo (2008). A tipologia tem também seus limites porque não deixa ver todas as particularidades existentes em cada uma das línguas comparadas, particularidades concomitantes no funcionamento dos diferentes tipos de negações nos diversos contextos sintáticos, nas declarativas, seja verbais, seja nominalizadas, nas proibitivas e nas nominalizações lexemáticas não predicativas.

\subsection{Tipologia das formas e das funções da negação}

Nossa tipologia pode ser uma tipologia das formas, dos sufixos, prefixos e/ou morfemas descontínuos que se distinguem nas diferentes línguas, das partículas que precedem ou seguem o elemento negado. Mas pode ser também uma tipologia das funções diferenciadas em cada língua considerada. É evidente que o número das funções que se distinguem depende tanto dos morfemas empregados quanto das estratégias usadas com cada morfema de negação. Vamos apresentar aqui as duas possibilidades. 


\section{Orações declarativas}

\subsection{Predicação no modo real}

\subsubsection{Sufixos e partículas Tupi}

Em primeiro lugar é impressionante a extensão do sufixo negativo -om e suas variantes -erom, -rom, -aũ, - $\tilde{u}$. Estes sufixos são típicos das subfamílias não-Maweti-TupiGuarani. Até a partícula $\mathrm{Mu} \tilde{g} u$ [yə] parece ser cognata do -om/- $\tilde{u}$ das outras subfamílias Tupi. Deste modo, o sufixo, com as suas variantes, parece representar o tipo de negação original do tronco Tupi.

Makurap: -rom (Braga 2005: 148)

$\begin{array}{llll}\text { (01) potkap } \quad \text { koa } & e & \text { xiw-a-rom } \\ \text { peixe } & \text { FOC } & 3 \mathrm{~s} & \text { cozer-IMPERF-NEG } \\ \text { 'o peixe não coze' } & & \end{array}$

Wayoró: -(e)r̃̃m, -õm (Nogueira 2011: 62)

(02) te-tãnnõ-r̃̃om

3-ficar.prenhe-NEG

'ela não ficou prenhe'

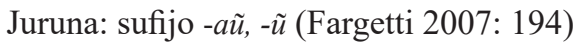
(03) kaībi
ali api
abaku-aũ
ontem
menino onça
matar-NEG
'ontem o menino não matou a onça'.

Xipaya: -(a) u, -ma, -kaa (Reis Rodrigues 1995: 144-148)

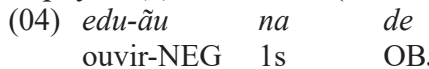

'eu não o ouvi'

Gavião óo, óònp (Moore 2002: 141)
(05) gakoráá óòn máà a-vit aka óòNv-á kí-po-á caçar NEG (3s)-AUX+pas 3c-comida matar NEG-fim EV-rem-FIN 'Pois, não caçou, não matou a sua comida' (tradução mínha)

Suruí-Paiter óm, óne: partícula que precede o elemento negado:

(06) óne orewaowao dé pa-ló-aka erúy zé áni é(Bontkes 1985: 184)

NEG Urueuwauwau T/A 1pl.incl-GENR-matar pouco INT POT EV

'Os urueuwauwau realmente não mataram nenhum dos nossos.'

Tupari: -ro-'om/-to'om (A. Singerman, c.p.)
(07) haytokia
s-etès-to-'om-ka
pnẽ-a-t-'en
muito 3-trazer-NOM-NEG
VBLR-EV-PAS-2s.SUBJ
'você não trouxe muito (não-atestado)'

Akuntsú: -erom/-rom/-om (Aragon 2014: 295-297)

(08) nom et-rom

NEG dormir-NEG

'não dorme'. 
DIETRICH - TIPOLOGIA MORFOSSINTÁTICA DA NEGAÇÃO NAS LÍNGUAS DO ...

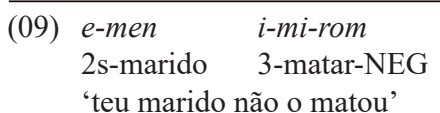

Mundurukú: partícula $\tilde{g} u$ [yə] (Crofts 2004: 229)

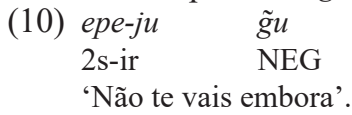

\subsubsection{Outros sufixos e posposições Tupi}

Algumas línguas Tupi usam outros elementos. São estas o Karitiana (Arikém), o Karo (Ramarama) e o Mekéns (Mondé). A posposição padni do Karitiana, em certos contextos fonológicos, pode produzir um - $\tilde{\imath}$ epentético no verbo, o qual pode substituir-se à negação por padni quando este último é omitido: $i$-terekterey- $\tilde{\imath}$ 'eu não dancei' (Everett 2006: 329). A negação por padni encontra-se no ex. (11):

Karitiana (Everett 2006: 332)

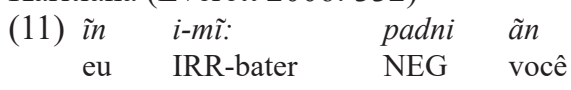

'Eu não vou bater em você'.

O Karo se caracteriza pelo uso de i?ke (Gabas, Jr. 1999: 184-185):

(12)

$\begin{array}{lll}\text { oken i?ke: } & o-k e t-t & i \text { i ke } \\ & \text { 1s-dormir-IND1 } & \text { NEG } \\ & \text { 'Não dormi.' } & \end{array}$

(13) ar otoy i?ke: at

$\begin{array}{lll}a t & \text { o-top-t } & \text { i?ke } \\ \text { 1s.PRON } & \text { 3s-ver-IND1 } & \text { NEG } \\ \text { 'Ele não me viu.' } & & \end{array}$

No Mekéns observamos o uso do sufixo -ap(o) (Galucio 2001: 92-94):

(14)

$\begin{array}{lll}\begin{array}{l}\text { ameko } \\ \text { onça }\end{array} \quad \text { matar-TEM-PAS-NEG } & \text { pedro } \\ \text { 'Pedro não matou a onça'. } & \text { Pedro }\end{array}$

\subsubsection{Os sufixos -ã, -a, jã, -xa (línguas Tupi-Guarani)}

Algumas línguas Tupi-Guarani caracterizam-se pela negação predicativa verbal (e não-verbal) por meio de $-\tilde{a}$ e suas variantes:

Aché (Rößler 2008: 92)
(15) too
$k w a-j a \tilde{a}-w e$
to wati
$1 \mathrm{s.PRON}$ saber-NEG-PAS 1s.PRON flecha
'Esqueci minhas flechas' 
Guaraní ocidental (Dietrich 1986: 143)

(16) $o-\tilde{e}-a$

3 -sair-NEG

'não sai'

Siriono (Schermair 1949: 119)

(17) a-tjandu-ã-nte

1s-ouvir-NEG-FOC

'não o ouvi'

Anambé (Julião 2005: 108)

(18) uru-ne- r-arũ-xa

1pl.incl-2s- REL-esperar-NEG

'não te esperamos'.

No Anambé, porém, observam-se também restos da antiga negação descontínua:

(19) t-ena-xa-i

REL-haver-NEG-NEG

$h a-r-\tilde{y}$

1s-REL-dente

'não há meus dentes', 'não tenho dentes', 'estou desdentado'.

\subsubsection{Partículas que precedem o predicado}

Trata-se, nos exemplos (20) a (24), de partículas derivadas de negações existenciais (cf. 2.2.):

Língua Geral Amazônica

(20) niti a-mo-pucú

NEG 1s-CAUS-comprido

'Não o alongo/encurto'

(21) niti xe camby

NEG 1s leite

'Não há meu leite/ não tenho leite'

Nheengatu (da Cruz 2011: 406)

(22) kua jane-retama ti-turusu

DEM 1pl-território NEG-grande

'nosso território não é grande'

Kokama: tima (Vallejos 2010: 171)

(23) tima ra-tseta eju-n

NEG 3s.m-querer comer-NOM

'ele não quer comida'

Omagua (O’Hagan 2011: 104)

(24) wainu-kana roa sita usu

mulher-pl NEG querer ir

'as mulheres não querem ir-se embora' 
DIETRICH - TIPOLOGIA MORFOSSINTÁTICA DA NEGAÇÃO NAS LÍNGUAS DO ...

Emerillon: wai (Rose 2011: 283)

(25) wai pe-d-ehe za-mã?ẽ-tanẽ

NEG 2pl-REL-DIR INDET-ver-DESID

'não queremos ver vocês (porque são demônios)'

O Omagua é a língua que adotou o elemento $r o(a) / r u(a)$ como negação geral nas orações declarativas (veja-se O'Hagan 2011: 104-105), elemento usado como negação de constituintes em algumas das línguas Tupi-Guarani. Não é aqui o lugar para discutir o problema da origem, talvez não Tupi-Guarani do Omagua e do Kokama.

\subsubsection{Os morfemas descontínuos das línguas do subgrupo Maweti-Tupi-Guarani}

Na grande maioria das línguas do subgrupo Maweti-Tupi-Guarani se desenvolveram morfemas descontínuos, ficando reservados sufixos negativos a orações não-declarativas e à negação nominalizada (cf. seções 2 e 3). As línguas do subgrupo Tupi-Guarani que têm uma negação descontínua usam o morfema típico $n(d) \ldots i$, enquanto o Sateré-Mawé usa it ... Pi e o Awetí ?an - ka. São todas as línguas Tupi-Guarani com a exceção do Aché, Guarani Ocidental, Siriono, Anambé, Kokama, Omagua, Ka’apor e Nheengatu. Em Tembé, Boudin (1978) ainda apresenta exemplos com - $i$ final (cf. ex. 30), o qual, com a evolução fonológica, passou a /ð/ na língua moderna.

Kaiowá (Cardoso 2008: 95)

(26) nd-o-je-porú- $i$

'Não usaram'.

Avá-Canoeiro (Borges 2006: 169)

(27) ne-jawara-un r-aira mirun

$n-o-u-i$

2s-gato-preto REL-filhote lagartixa

NEG-3-comer-NEG

'O teu gatinho não comeu a lagartixa'.

Yuki (Villafañe 2004: 177)

(28) ma baruguasu a-ru-hiri-re

NEG banana 1s-comer-NEG-FUT

'Não comerei banana'.

Warázu (Ramirez \& de França 2017)

(29) nä-ða-wata-?i

NEG-1pl.incl-andar-NEG

'não andamos'.

Tembé (Boudin 1978: 173)

(30) $n$-u-ikó-i

NEG-3-estar-NEG

'não está'.

Kamayurá (Seki 2000: 330)

(31) n-a-etsak-i-te

NEG-1s-ver-NEG-FOC

'não o vi'. 
Sateré-Mawé: it ... Pi (Carneiro 2012: 80)

(32) Nilda it Ø-i-hairu-?i

Nilda NEG-3-dançar-NEG

'Nilda não está dançando'.

(33) kurum it i-kahu-?i

menino NEG 3-bonito-NEG

'o menino não é bonito'.

Awetí (Drude 2008: 89)

(34) Pan mimõ o-to-ka

NEG ontem 3-ir-NEG

'não se foi/foram embora ontem'.

(35) Pan e-mẽpit-zoko-ka Pén (Monserrat 2012: 30)

NEG 2s-filho-FUT-NEG você

'Você não terá filhos'.

\subsection{Negação fora do modo real (futuro e modo irreal)}

A negação das declarativas descrita até agora limita-se geralmente ao passado e ao presente. Em perspectivas de futuro e de modos não reais, os morfemas descritos não são suficientes. Em alguns casos se agregam elementos que significam 'pensar, crer', de modo que as expressões negadas denotam valores como 'nem pensar em (fazer alguma coisa)' (ex. 36-37). No Karo, se usa a partícula yahmām, que indica o proibitivo em outros casos (cf. ex. 141), para o futuro imediato negado (cf. ex. 39). No futuro simples a negação i?ke segue a partícula de futuro yat (cf. Gabas, Jr. 1999: 247).

Guaraní paraguaio (Canese/Acosta 2001: 95)

(36) n-o-mba'apo-mo' $\tilde{a}-i$

NEG-3-trabalhar-NEG.FUT-NEG

'não está disposto a trabalhar'.

Mbyá (Dooley 2006: 38)

(37) nd-a-rovia- mo'a-i-rã

NEG-1s-acreditar- NEG.FUT-NEG-FUT

'Certo não vou acreditar'.

Wayãpi (Grenand 1980: 89)
(38) pi'a
n-o-kalu-
$\tilde{a} i$
menino NEG-3-urinar- NEG.FUT
'o menino não vai urinar'.

Karo (Gabas, Jr. 1999: 247)
(39) pún o-?e-a $o$-kap- $t$ atirar 1s-AUX-GER 1s-AUX.FUT-IND1 NEG 'eu não vou atirar'.


No Guarani paraguaio se conhece o tipo $n[d]$... i chéne (com a suposição epistêmica exprimida por -ne); no Guarayu se usa $n[d]$...ichi-ra; no Juruna o sufixo-ma em predicados do modo irreal:

Guarani paraguaio (Canese 2001: 95)

(40) n-o-mba'apó-i chéne

NEG-3-trabalhar-NEG NEG.FUT

'Não trabalhará'.

Guarayu (Hoeller 1932: 96)

(41) nd-a-tsepia- ichi-ra

NEG-1s-ver- NEG-FUT

'Não verei'.

*Tupinambá

(42) nd-a-juka-i xoéne

NEG-1s-matar- NEG.FUT

'Não o matarei'.

Juruna (Fargetti 2007: 199)

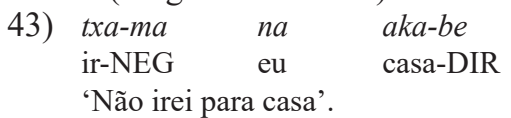

\subsubsection{Negação existencial}

A negação existencial é uma subcategoria da negação das cláusulas declarativas que só em algumas línguas do tronco Tupi tem uma expressão própria. Para as línguas Tupi temos documentação no Makurap:

Makurap (Braga 2005: 151)

(44) potkap pit

peixe-NEG

'não há peixe'

Proto-Tupi-Guarani

(45) $* n(a)-i-t y b-i$

NEG-3-existência.múltiple-NEG

'não há'.

Por outro lado, nas línguas Tupi-Guarani observamos formas não flexíveis derivadas de construções do tipo (ex. 45) *n(a)-i-tyb-i, construções que significam 'não existe', 'não há'. A forma *n(a)-i-týb-i tornou-se natyvi no Asurini do Xingu, nati no Omagua antigo, niti na língua geral amazônica. Nesta última, porém, a forma não está atestada como negação existencial, mas como negação declarativa estandardizada (cf. Dietrich 2014: 614). No Guajá observamos na 'axi 'não há', no Emerillon, dati 'não há' também se explica a partir de $<* n d a-(i-t y b)-i$. 
Mbaéty 'não há', 'não existe' é uma negação existencial que se formou no Guarani Ocidental (chiriguano), provavelmente a partir da expressão $m b a$ 'e-i-tyb-i 'coisa não existe, 'não há nada', que assume a função da negação existencial, mas que entra também na forma de indefinidos do tipo mbáety mbáe '(não há) nada', mbáety kía '(não há) ninguém' (Dietrich 1986:144-145). Compare-se Yuki -biti, que é uma negação de constituintes e uma negação enfática (Villafañe 2004: 178-179).

Mbaety (ex. 46) gramaticalizou-se, tornando-se morfema negativo preposto ao predicado. O processo da gramaticalização deve ter se dado entre 1791 (León de Santiago 1791/2005) e o fim do século XIX, quando mbáety aparece pela primeira vez na gramática de Corrado (1896: 77-78): (ex. 47).

(46) Guar. Ocid.. Mbáety 'não há', 'não' < mbáe 'coisa' + n-i-týb-i NEG-3-montão-NEG, mbáety mbáe '(não há) nada', mbáety kía '(não há) ninguém’ (cf. Dietrich 1986: 144-145).

(47) mbáety há-u 'eu não comia', háe mbáety che-r-écha 'ele não me viu', mbáety che mandúa 'não há minha lembrança, não me lembro'; mbáety tembiu 'não havia comida'.

Tapiete (González 2005: 251)

(48) mba'eti a-juka

NEG 1s-matar

'eu não matei (ninguém)'.

Yuki: partículas $m a$, ma ta

(49) iba-ñongue ma ma (Villafañe 2004: 181)

fruta-pl NEG

'não há mais fruta'.

Kamayurá (Seki 2000: 333)

(50) anite pakúa-pem

NEG paca-LOC

'não há paca alí'.

Guajá: na'axi (Magalhães 2007: 283)

(51) na'axi ha-py'yr-a

NEG 1s-conta-CAS

'não há minha conta', 'não tenho contas'.

Omagua antigo: nati (O'Hagan 2011: 106)

(52) Nati marai aikiara Dios mura

COP coisa DEM.PROX.MS Deus 3s.MS

'Deus não é nenhuma de estas coisas' [Lit. 'Deus não é coisa'].

Asurini do Xingu: posposições imame e natyvi (Pereira 2009: 270)

(53) myve karai asuka imame

antes.de não.indígena açúcar NEG

'antes dos não índios não havia açúcar'.

(54)
tavera-ipe
mama'e-'yva
natyvi
antiga.aldeia-LOC GENR-fruta NEG
'não há fruta na antiga aldeia'. 
DIETRICH - TIPOLOGIA MORFOSSINTÁTICA DA NEGAÇÃo NAS LÍNGUAS DO ...

Emerillon (Rose 2011: 281)

(55) dati tarawads-a-r-ehe-te,

a-pihig

COP trabalho-REF-REL-a causa de-FOC, 1s-apanhar

sikadzi maire

'como eu não tinha trabalho, assumi o posto de prefeito'.

(56)
a?e-nam
dati docteur,
aipo
kob docteur oporam-te
DEM-quando COP médico agora COP médico e/com-FOC

\author{
infirmier \\ enfermeiro
}

'então não havia médico, agora tem médico e até um enfermeiro'.

A segunda negação existencial do Asurini do Xingu, imame, segundo Alves Pereira (2009: 270) se distingue de natyvi pelo traço da 'ausência de algo conhecido', pela 'falta', enquanto natyvi se refere à inexistência de algo que não se conhece, ao 'não saber da existência de algo'. Ambas as negações existenciais se pospõem ao elemento cuja existência é negada, enquanto as negações na'axi, nati, dati e mbáety se prepõem.

Acho importante o capítulo da negação existencial não só pela existência mesma da negação existencial, mas também porque eis aqui a origem de alguns morfemas de negação em orações declarativas (veja-se acima o capítulo 2.1.4.).

\section{Negação nominal}

\subsection{Predicação negativa com predicados nominalizados}

A maioria das línguas aqui estudadas apresenta sufixos negativos específicos nas "subordinadas" nominalizadas. Preparando a descrição da negação nominal, lexemática (veja-se 3.2.e 3.3.), descrevemos aqui a negação dos predicados nominalizados caracterizados pelos mesmos sufixos que aqueles que se usam na negação lexemática ( ${ }^{*}-e^{\prime} y m$ ).

Parakanã (Souza e Silva 1999: 101)

(57) we-nopó-iłim-amo, n-a-tfatfá-ihi

1s-surrar-NEG-CIRC NEG-chorar-NEG

'se ele não me bater, eu não choro'.

Tapirapé
(58) $\tilde{a}-x \tilde{a} o$
we-xe-pymĩ-
e'ým- $a$
1s-banhar-se 1s.NM-1s-afogar-se-
NEG-CAS
'banho-me sem me afogar'.

Kayabí (Weiss 2005: 21)
(59) a'ere n-oo esak-e'em-a
então 1pl.incl-ir ver-NEG-CAS
'então não fomos ver'.

Asuriní do Xingu (Pereira 2009: 186)

(60) dje a-djat te-furaai-e'ỹma

1s.PRON 1s-vir ?-dançar-NEG

'eu não vim para dançar', Lit. 'eu vim não para dançar'. 
Kagwahiva-Tenharim (Betts 2012: 83)

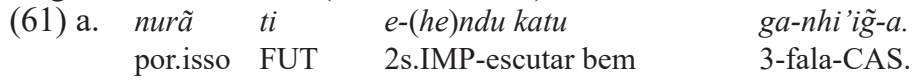

b. a'ero ga nde-nupã nde-hendukatu-e'ym-ame!

então 3.PRON 2s.PRON-surrar 2s-escutar.bem-NEG-CIRC

'Por isso escute bem suas palavras! Senão, ele te surra se você não obedece'.

Wayãpi: o hortativo em $t$ - negado mediante $-\tilde{y}$, com a partícula obrigacional nẽ no final:

(62)
t-ele-nира̃- $\tilde{y} \quad n \tilde{e}$
(Copin 2012: 265)
HORT-2s-surrar-NEG OBR
'não precisa que o surres'.

Guajá (Magalhães 2007: 285)
(63) karai iwyr-aha-'ým-a ari-xa-ta are-ka'a-r-ehe homem.branco voltar-ir-NEG-CAS eu-ver-FUT 1pl.excl-selva-REL-DIR 'eu desejo ver a não-volta do homem branco à nossa selva' .

Aweti (Monserrat 2012: 33)

(64) ite-kát-ePim-iwo, 1s.REL-coisa-NEG-CIRC $\begin{array}{ll}a-m o t o ́-k a & e-k i t i t \\ \text { 1s-dar-NEG } & \text { 2s-DIR }\end{array}$ 'como não tenho coisas, não te dou'

Karitiana

$\begin{array}{cllll}\text { (65) } \begin{array}{c}\text { jonso } \\ \text { mulher }\end{array} \quad \text { comida } & y \text { - } k i & \text { comer-NEG } & \text { 3-engy } & \text { 3adni } \\ \text { 'a mulher que não comeu a comida não vomitou'. } & \text { NEG }\end{array}$

As línguas que não têm um morfema próprio da negação nominal, negam "subordinadas" nominalizadas com o mesmo morfema com que negam também orações declarativas principais, por exemplo:

Ka'apor (Kakumasu 1986: 376)
(66) $u$-?u-?im-ha
Ø-jirik
$o-h o$
3-comer-NEG-NOM 3-secar
3-ir

'aquele que não comia ia se encolhendo mais e mais'.

Tupari: - 'om (A. Singerman c. p.)

(67) apsikum'ẽ-'om

ouvido-NEG

'que não tem ouvido', 'surdo'.

Gavião: ốò (D. Moore, c.p.)
(68) paá-ykini-t ồop ná
1pl.incl-ver-AG NEG VBLR
'nós estando sem visitantes'. 


\subsection{Formação de antônimos}

Poucas línguas do tronco Tupi distinguem, na formação lexemática negativa, entre a formação de antônimos do tipo possível-impossível, real-irreal e a privativa. A formação privativa bem conhecida em línguas como o inglês, colour - colourless, wit - witless, child-childless, é mais ou menos inexistente em português, língua que só tem expressões analíticas como sem graça, que não tem filhos, mas sim incolor ou descolorado. Porém, parece que a distinção entre antônimos e privativos não tem muita importância nas línguas Tupi. Pode ser uma casualidade das descrições existentes, mas na documentação que temos o Yuki, o Siriono e o Guarani Ocidental são as únicas línguas que permitem uma distinção clara entre as duas funções porque têm dois sufixos diferentes. Destes, um é o sufixo da negação predicativa (-riã/-niã respectivamente $-\tilde{a}$ ), o outro o sufixo -ba, respectivamente -bae, claramente privativo:

Yuki: -riã, -niã é um sufixo derivacional para formar antônimos como

(69) e-moi-ji-riã

3-cook-NOM-NEG

'não-cozido, cru'.

(70) gurakõ-niã (Villafañe 2004: 182)

força-NEG

'sem forças, fraco'.

Formações com *-ma?e no Guarani Ocidental, Warázu, Yuki, Siriono, Asurini do Xingu, Tembé e Kamayurá (cf. os exemplos 71 e 72):

Yuki: -ba (Villafañe 2004: 182)

(71) sikije-ba

medo-NEG

'(estar) sem medo, (ser) intrépido'.

Siriono: -bae

(72) enindisi-bae

esposa-NEG

'que não tem esposa, sem mulher'.

Veja-se a mesma oposição no Guarani Ocidental (Dietrich 1986: 143, 179):

(73) háe h-ésa

ele/ela 3-olho

'tem olho/vista, pode ver'.

(74) háe h-esá-a

ele/ela 3-olho-NEG

'não tem vista'.

(75) háe h-ésa-mbáe

ele/ela 3-olho-NEG

'está desprovido de vista, (é) cego'. 
O caráter privativo de -mbáe é evidente no Guarani Ocidental quando se vê que a formação não é possível com lexemas que exprimem uma qualidade e não um objeto que pode "faltar"; assim

(76) i-kávi 3-bom 'é bom' - i-kavĩ-a 3-bom-NEG 'não é bom, é ruim', mas não *i-kávi-mbáe.

\subsection{Formação de privativos}

Além do Guarani Ocidental e do Siriono, também no Asurini do Xingu e no Tembé existe um sufixo reconstruído *-ma?e, desenvolvido a partir de *-ma?e 'coisa', que pode formar privativos.

Asurini do Xingu: ima'e (Pereira 2009: 215)

(77) u-manu-ima'e

3-morrer-NEG

'aquele que ficou imortal'.

Tembé: - $m a$ 'ê (Boudin 1978: 128)

(78) (u-)mano-'ima'ê

(3-)morrer-NEG

'que não morre', 'imortal'.

Observe-se que praticamente todas estas formações são predicativas e só ocasionalmente podem aparecer como atributos não predicativos. Por consequência, se pode formular a hipótese de que a formação lexemática negativa está reduzida a casos excepcionais.

\subsection{Não distinção formal entre antônimos e privativos}

A maioria das línguas não distingue entre antônimos e privativos. Ao passo que só algumas das línguas não Tupi-Guarani usam morfemas específicos para a negação lexemática, a grande maioria das línguas Tupi-Guarani têm o sufixo reconstruído *-ełim para esta função. O Avá-Canoeiro não tem reflexos do sufixo *-e'tim, mas usa formas com $n$... i (Couto e Silva 2014 e comunicação pessoal, agosto de 2016). Não temos informação sobre a negação lexemática no Araweté.

\subsubsection{Sufixo *-e'ym}

Mbyá (Dooley 2006: 45)

(79) o-ma'e-e' $\tilde{y}$-va'e 3-ver-NEG-ATR 'que não về', 'cego'.

Guarayu (Hoeller 1932: 96)

(80) tata-'e' $\tilde{y}-m e$

fogo-NEG LOC

'no não-fogo', 'onde não havia fogo'. 
DIETRICH - TIPOLOGIA MORFOSSINTÁTICA DA NEGAÇÃo NAS LÍNGUAS DO ...

*Tupinambá

(81) juka-çar-e 'ým-a matar-NOM-NEG-CAS

'o não-matador, aquele que não mata'.

Suruí-Aikewara (Lopes 2014: 100)

(82) i-apihaw-eitm-a'e

3-cabelo-NEG-ATR

'calvo, que não tem cabelo'.

Tembé (Boudin 1978: 104)

(83) kirimaw- ‘̆m

força-NEG

'que não tem força, impotente'.

Kokama (O’Hagan 2011: 111)

(84) sui-ima ura

rabo-NEG 3s.MS

'Ele é sem rabo', 'não tem rabo'.

Como já vimos, o sufixo *-e ym é indiferente com respeito à distinção entre antônimos e privativos. Orações negadas nominalizadas mediante * $*_{\text {-Pim }}$ admitem o nominalizador atributivo *-va?e quando a formação for usada como atributo (exemplos 79 e 82).

\subsubsection{Outros recursos (sufixos): formações lexemáticas}

Guaraní Ocidental (Dietrich 1986: 143)

(85) oi-kuá-a-va

3-saber-NEG-ATR

'aquele que não sabe, ignorante'.

Aché (Rößler 2008: 89)

(86) y llã

água-NEG

falta d'água, que não tem água, enxuto, árido'.

Aché (Rößler 2015: 377; c.p.)

(87) lle/ lle'e ‘tripas, satisfeito' $\rightarrow$ lle-llã 'estar sem tripas, faminto', prãjã 'não bom, ruim' $\rightarrow$ prãjã-llã 'não-não-bom', 'bom, ótimo'.

Língua Geral Amazônica

(88) typy-eýma (s. XVII) > niti typy (s. XVIII) 'pouco profundo'.

Observa-se aqui a passagem de uma formação morfológica, sintética a uma formação sintagmática, analítica. Outras línguas simplesmente não têm recursos específicos para a negação lexemática, mas usam os morfemas de que dispõem também para a negação predicativa das orações declarativas. Trata-se de poucas línguas Tupi-Guarani. As outras são línguas Tupi: 
Anambé (R. Julião, c.p.)

(89) $i$-kiry-xa wĩ

3-forte-NEG 3s.PRON

'está débil, fraco'.

(90) i-apy-rixa wĩ

3-torto-NEG- 3s.PRON

'está recto'.

Emerillon (Françoise Rose, c.p.)

(91) desapatodziähã idze takwan

d-e-sapato-ḑi-ãhã iḑe ta-a-k $k^{w a}$-n

NEG-1s-sapato-NEG-só 1s.PRON FIN-1s-passar-CONT

'Vou andar sem sapato'

Suruí-Paiter -om: (Bontkes/Bontkes 2009: 22)

(92) ò-máid-õm

1s-filha-NEG

'sem minhas filhas'.

Wayoró: -er̃̃m (Nogueira 2011: 58)

(93) $k a \tilde{a}[\beta]-\tilde{e} \tilde{r o} m$

comprido-NEG

'não comprido', 'curto'.

Makurap:-om (A. Braga, c.p.)

(94) awtig-om

forte-NEG (de awtik 'forte')

'fraco'.

Mekens (Galucio 2001: 92)

(95) sĩr-ãp

pequeno-NEG

'grande'.

Sabemos que as línguas Tupi que têm morfemas próprios são as seguintes:

Karitiana: $-k i$ (cf. ex. 65)

(96) ñonso ti'y 'y-ki

mulher comida comer-NEG

'a mulher que não comeu a comida'.

Juruna -ma (Fargetti 2007: 201)

(97) i-tabá-ma

3s-cabeça-NEG

'um sem cabeça, desnorteado'.

(98) Mẽtukitire i-txukáhã-mã-hãma

kayapó 3s-arco-NEG-RED

'os Kayapó são sem arcos'. 
Mundurukú: - ‘ũm (Dioney Gomes 2006: 92)

(99) wuy- 'ũm

longe-NEG

'(o que) não está longe'.

\section{Negação de constituintes}

Um capítulo específico sobre a negação de constituintes focalizados justifica-se porque existem algumas línguas que permitem a distinção, por meio de morfemas específicos, entre a negação predicativa de orações declarativas e a negação de constituintes, sujeitos, objetos ou complementos circunstanciais. As outras línguas fazem a distinção mediante a posição da negação e/ou partículas enunciativas específicas, por exemplo o Sateré-Mawé (cf. Carneiro 2012: 105-109).

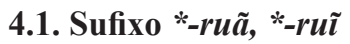

Parece que as línguas do subgrupo Tupi-Guarani, em algum momento, criaram o sufixo de focalização *-ruã/*-ruĩ. Um grupo relativamente pequeno do subgrupo TupiGuarani caracteriza-se pela conservação deste sufixo, cuja função é precisamente a negação de argumentos focalizados. O sufixo aparece também na gramática do Guarani clássico de Ruiz de Montoya (1640), mas há dúvida que o sufixo -ruguã funcionasse realmente nessa língua e não fosse apenas uma invenção do Montoya, com base no modelo da gramática do Tupinambá do padre Anchieta. Contudo, o morfema na ... -ruguãi se menciona ainda na gramática de Restivo (1724 [1996: 41-42]), que está, certo é, na tradição de Montoya. As línguas em que o sufixo de negação focalizada funcionava e funciona hoje são o Yuki, talvez o Warázu, o Kayabí, o Kamayurá, o grupo Kagwahíva, o extinto Tupinambá e a LGA, o Wayãpi, Emerillon, Zo’ê e Guajá. No Guarayu funcionava até o século XIX. Em vários casos a negação é descontínua, do tipo na ...rũi, $n$... ruã , quando se trata de um predicado negado. Vejam-se os exemplos (100) e (101):

* Língua geral amazônica

$\begin{array}{cl}\text { (100) na-xe-ruã } & \text { a-monhang } \\ \text { NEG-1s-NEG } & 1 \text { s-fazer } \\ \text { 'não fui eu que o fiz'. } & \end{array}$

Kayabí (Weiss 2005: 78)

(101) na awauwe rũi ore o-i

NEG hoje NEG 1pl.excl ir-NEG

'não é hoje que vamos'. (Lit. 'não é hoje que não vamos')

Kamayurá (Seki 2000: 334)
(102) ene
ruẽj
oro-etsak
2s.PRON NEG 1s.SUJ/2s.OBJ-ver
'não é você que eu vejo'. 
Warázu (Ramirez \& de França 2017)

(103) tse ma?e- rä́we

1s coisa-NEG

'não é meu'.

Wayampipuku (Jensen 1994: 355)
(104) ja'yr-er-ruã
amẽ
tamõ kõ.
o-ji-movija-pa criança-COL-NEG então avô pl 3-REFL-crescer-PERF 'nossos avôs então não eram crianças. Já se fizeram adultos'.

Emerillon (Rose 2011: 280)

$\begin{array}{ccc}\text { (105) wirakara-nũwã-?e } & \text { zowoma?ẽ-kom } & o \text {-ba?e } \\ \text { Deus-NEG-INT } & \text { Wayana-pl } & \text { 3-fazer } \\ \text { 'não (foi) Deus (que) criou os Wayana'. } & \end{array}$

\subsection{Outros sufixos}

No yuki observamos o uso de -biti, sufixo cognato de Guarani mbáety (veja-se ex. 46):

Yuki -biti (Villafañe 2004: 178)
(106) baruguasu-biti
no-che
a-cha-ta
milho-NEG
FOC-1s.PRON 1s-comprar-FUT
'não é milho que vou comprar'.

\subsection{Partículas (morfemas independentes)}

Kokama (Vallejos 2010: 534)

$\begin{array}{clll}\begin{array}{c}\text { (107) parana tsima-ri } \\ \text { rio ribeira-DIF }\end{array} & \text { inu } & \text { upuka } & \text { ni-tuntachiru-jara } \\ \text { sair } & \text { NEG-cueca-ter }\end{array}$

'Saem na ribeira do rio sem sequer vestir cuecas'.

A partícula $n i$ - evidentemente foi emprestada do espanhol ni (siquiera) 'nem sequer'.

Araweté : ja we (Solano 2009: 275)
(108) иги-тире̃
ja we iwira
1pl.excl-abater NEG árvore
'Nós não derrubamos árvore'.

Juruna: partícula náimã (Fargetti 2007: 200)

(109) Tarinu-náimã Yabaiwá-be txukáyá kua

Tarinú-NEG Yabaiwá-DAT flecha dar

'não foi Tarinú que deu flecha para Yabaiwá'. 
DIETRICH - TIPOLOGIA MORFOSSINTÁTICA DA NEGAÇÃo NAS LÍNGUAS DO ...

\subsection{Focalização mediante a posição do morfema negativo}

No Karo (Ramarama) se usa a partícula i?ke posposta à constituinte focalizada:

(110) õn-i?ke

1s.PRON-NEG cobra

top- $t$ (Gabas, Jr. 1999: 185)

'não fui eu que vi a cobra'.

\section{Finalidade negativa e orações proibitivas}

\subsection{Finalidade negativa}

As orações proibitivas são orações independentes em todas as línguas documentadas, enquanto o morfema negativo do Aweti exprime uma finalidade negativa, uma advertência relativa a um perigo iminente, em orações semanticamente complexas, parcialmente truncadas. Na superfície aparece uma alerta ou advertência em forma de desejo negativo (Monserrat 2012: 35-39). Na maioria dos casos se trata de expressões que se podem traduzir por "(cuidado que) não ...!".

Awetí (Monserrat 2012: 35)

(111) inĩ-tám o-tóge-ßeti

rede-cordão 3-rebentar-NEG

'cuidado que a corda rebenta'.

\subsection{Orações proibitivas}

A grande maioria das línguas distingue terminantemente entre a negação declarativa e a proibitiva. As que usam o mesmo morfema de negação em ambos os casos, exprimem a distinção por elementos modais ou expressões de mando. Porém, a distinção tipologicamente importante não está documentada em várias línguas (Zo’é), sobre tudo em línguas Tupi (Wayoró, Akuntsú, Makurap), para as quais não temos exemplos de construções proibitivas. Este fato talvez se explique pela não-existência ou o uso restringido do imperativo em várias línguas. Parece que é sobretudo um problema de certas línguas amazônicas fora da família Maweti-Tupi-Guarani. Não posso entrar aqui na problemática esboçada, por exemplo, por Crofts para o Munduruku (Crofts 2004) e Gabas Júnior para o Karo (1999: 134). Estes autores chamam a nossa atenção para a tendência dos falantes dessas línguas de evitarem o uso do imperativo por razões de cortesia com os demais adultos. A escassez do uso do imperativo, positivo e negativo, talvez possa ser explicada pela aparente "falta" na descrição de vários linguistas, e a "omissão" desta temática nas suas gramáticas. Alguns morfemas proibitivos combinam-se com o imperativo, outros como o indicativo. As línguas que usam o imperativo com a negação proibitiva aparecem sublinhadas no presente trabalho. 


\subsubsection{Proibitivas com negações iguais às orações declarativas}

As línguas que usam o mesmo morfema negativo nas proibitivas e nas declarativas são o Anambé, o Kagwahiva, o Ka'apor, o Tupari, o Xipaya e o Munduruku. Nestas línguas, a construção proibitiva se distingue da declarativa sobretudo pela entoação diferente. Observa-se o uso do imperativo em todas as línguas com a exceção do Tupari e do Munduruku (ex. 116).

Anambé (Julião 2005: 113)
(112) $e$-'u pirã-xa, iha-memy! 2s.IMP peixe-NEG 1s-filho 'não comas peixe, meu filho!'

Kagwahiva (Betts 2012: 180

(113) nda-ji-pyhýg-i!

NEG-1s.PRON-apanhar-NEG 'não me apanhe!'

Ka'apor (Kakumasu 1986: 358)
(114) anĩ,
e-raho-Pim
não, 2s.IMP-levar-NEG
'não, não leve!'

Xipaya (Fargetti 2007: 239)

(115) abuk(u)-aũ he de fechar-NEG IMP M.OBJ 'não a feche!'

Mundurukú (Crofts 2004: 191)

(116) $W a^{3}$ gut $^{2}$ ! 'não chore!', $W a^{3} \tilde{g u}^{2} j u y^{3}$ ! 'não chore, por favor!'; $J^{3} u^{2} h u m^{2}$ gu juy! 'não suba, por favor!'.

No Tupari o proibitivo se forma da mesma maneira que nas declarativas, agregando-se partículas modais de ordem (Adam Singerman, c.p.).

\subsubsection{Proibitivas morfologicamente distintas das negações declarativas}

Tapirapé -ewi (Praça 2007: 215)

(117) xe-nopy-ewi!

1s.PRON-bater-NEG

'não bata em mim!'

Kayabí-awi:

(118) ere-jor awi!

2s-vir-NEG

'não venha!' 
DIETRICH - TIPOLOGIA MORFOSSINTÁTICA DA NEGAÇÃO NAS LÍNGUAS DO ...

Asurini do Xingu -jũ (Pereira 2009: 283)

$\begin{array}{ll}\text { (119) avatxi } & \text { pe-tim-jũ! } \\ \text { milho } & \text { 2pl-plantar- NEG } \\ \text { 'não plantem milho!' }\end{array}$

Karitiana: $-y$

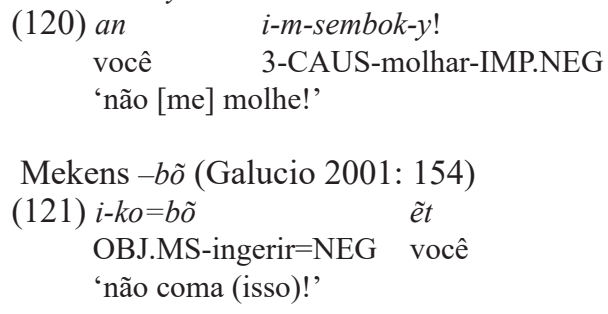

Suruí-Paiter ๆaba (Bontkes 1985: 201)
(122) é-gaba tóy-zápor
2s-NEG 1pl.excl-correia romper HORT
asá ré
tá-íyâ
3pl-EV
'não rompa a nossa correia! (disseram), diz-se'.

\subsubsection{O sufixo *-eme}

Certo número de línguas Tupi-Guarani forma as proibitivas mediante o sufixo *-eme, algumas com o imperativo, outras com o indicativo. Funciona no Guajá, no Asurini do Tocantins, Parakanã, Avá-Canoeiro, Araweté, Kamaiurá e funcionou no extinto Tupinambá. Existe no Guarayu, Warázu, Yuki, Mbyá, Guarani clássico, Aché e no antigo Guarani Ocidental. Parece complicado o caso do Wayãpi e do Emerillon. No Wayãpi temos documentado um único exemplo (Grenand 1980), exemplo (129), enquanto na descrição recente de Copin (2012) nem sequer se menciona o sufixo, talvez já um arcaismo na língua de cinquenta anos atrás. Hoje as proibitivas se formam pelo hortativo/optativo com o prefixo $t$ - e o sufixo nominal negativo $-\tilde{y}$ seguido da partícula obrigacional $n \tilde{e}$ 'não precisa; melhor que não!' (ex. 131). No Emerillon, o morfema mame aparece antes do predicado. Há dúvida de que contenha o antigo sufixo *-eme.

Mbyá (Dooley 2006: 34)

(123) ei-pe'a-eme okẽ!

2s.IMP-abrir puerta

'não abra a porta!'

Aché (Rößler, c.p.)

(124) japo-eme!

fazer-NEG

'não faça (isso)!'

Warázu (Ramirez/de França 2017)

(125) e-wata-me!

2s.IMP-andar-NEG

'não ande!' 
Asurini do Tocantins (Cabral/Rodrigues 2003: 47)

(126) e-apokató-eme!

2s.IMP-arranjar-NEG

'Não arranje (isso)!'

Parakanã (Souza e Silva 1999: 67)

$\begin{array}{lll}\text { (127) e-maná-emé } & \text { mo̊án- } a & \text { i-tfopé! } \\ \text { 2s.IMP-dar-NEG } & \text { remédio-CAS } & \text { 3-PRON.DAT } \\ \text { 'não dê remédio para ele!' } & \end{array}$

Kamayurá (Seki 2000: 333)

(128) ne-r-eakajym-em!

2s-REL-esquecimento-NEG

'não se esqueça dele!'

Wayãpi (Grenand 1980: 90)

$\begin{array}{ll}\text { (129) o-pyñ } & \text { o-memy i- 'a-ta-me } \\ \text { 3-reter 3-filho 3-cair-FUT-NEG } & \\ \text { 'retenha seu filho para ele não cair!' }\end{array}$

Emerillon: mame(n)- (Rose 2011: 282)
(130) mamen-a-ko si-ze-ro-Par!
NEG-REF-INJ 1pl.incl.-REFL-CAUS.COM-cair
'não combatamos um contra o outro!'

Wayãpi (Copin 2012: 265)

(131) $t$-uu- $\tilde{y}$-kupa nẽ

HORT-vir-NEG-pl OBR

'não precisa que eles venham', 'não venham eles!'.

\subsubsection{Morfemas descontínuos}

No Sateré-Mawé há morfemas descontínuos para a expressão proibitiva:

(132) Sateré-Mawé: it ...teißo proibitivo, it ... te optativo negativo (Carneiro 2012: 92-94).

\subsubsection{Partículas proibitivas pospostas ao predicado}

A maioria das línguas que não conservaram ou nunca tiveram o sufixo *-eme usam partículas pospostas ao predicado. Não se veem cognatos, todas parecem particulares. A partícula inami é comum do Kokama e do Omagua (ex. 139).

Yuki (Villafañe 2004: 179)

(133) $k u$ che-be-rasi chĩu!

DEM 1s.PRON-CAUS-doente NEG

'não me ponha doente!' 
Siriono: nãã, -ra (Schermair 1949: 130-133)

(134) nikáre-he-ra eré-kwa-tĩ hẽ! jacaré-DAT-NEG 2-atirar-FRUST eh!

'eh, não atire ao jacaré!'

Suruí-Aikewara: puhi (Lopes 2014: 116)
(135) e-suka
puhi!
2s.IMP-matar
NEG
'não o mate!'

Tembé: - dó, -zo, com o imperativo positivo
(136) $e-$ '?u
dó
2s.IMP-tocar-
IMP.NEG
'não coma (isso)!'
(137) e-zatoy-
$z o !$
2s.IMP-tocar-
IMP.NEG
'não toque!'

Araweté: -ina (Solano 2009: 281)
(138) pe-karu- ina!
2pl-chorar- NEG
'não chorem!'

Omagua: inámi (O’Hagan 2011: 114)
(139) inami ukiri
NEG dormir
'não durma!'

Juruna: máku (Fargetti 2007: 239)

(140) ita máku u-txukãhã, u-mé

levar-NEG, 1s-arco 1s-POS

'não pegue meu arco, é meu!'

Karo: yahmām (Gabas, Jr. 1999: 191)
(141) karo-kérat-t yahmãm
2pl-dormir-IND1 NEG
'não durmam!'

\subsubsection{Partículas que precedem o predicado}

Terminamos a nossa apresentação descritiva da negação nas línguas Tupi com partículas proibitivas antepostas ao predicado. Trata-se de duas partículas cognatas da LGA e do Nheengatu e de uma do Aweti:

Língua Geral Amazônica

(142) teinhé e-ikó xe-recé

NEG 2s.IMP-estar 1s.PRON-DIR

'não mexa comigo!', 'deixe de mexer comigo!' 
Nheengatu (Cruz 2011: 407)

(143) te-re-mbau kua

NEG-2s-comer DEM

'não coma isto!'

Aweti: kware (Drude 2008: 89-90), kwat (Monserrat 2012: 35)

(144) kwát e-tét-tu

NEG 2s-dormir-NOM

'não durma!'

Além disso se trata da partícula ani do Kaiowá, Guarani paraguaio, Guarani Nhandeva e Guarani Ocidental:

Guar. paraguaio (Canese 2001: 100)

(145) ani re-hó- tei

NEG 2s-ir.se.embora- FRUST

'Não vá embora!'

Guaraní Ocidental (Dietrich 1986: 144)

(146) ãni é-ju kwápe!

NEG 2s-vir aquí

'Não venha cá!' (dial isocenho)

assim que das partículas aguyje, awi, te, ajete ... imi do Guarani Ocidental (dial. Ava), do Tapiete, do Araweté e Tembé awizé! (Boudin 1978: 44) No Araweté a partícula restritiva ajete se usa junto com o sufixo negativo -imi:

Guarani Ocidental (Dietrich 1986: 146)

$\begin{array}{cll}\text { (147) añãwe pỹtu aguýje } & e ́-k e ! \\ \text { agora escuridão NEG } & \text { 2s.IMP-dormir } \\ \text { 'esta noite não durma!' } & \end{array}$

Tapiete (González 2005: 250) $\begin{array}{ll}\text { (148) awi } & e-m i-k w i ! \\ \text { NEG } & \text { 2s.IMP-mexer-FUT } \\ \text { 'não mexa!' } & \end{array}$

Araweté (Solano 2009: )

$\begin{array}{cll}\text { (149) ajete } & \text { jiti } & \text { e-hi-imi! } \\ \text { RESTR batata.doce 2s.IMP-assar-NEG } \\ \text { 'Não pode assar batata-doce!'. }\end{array}$

'Não pode assar batata-doce!'.

\section{Análise tipológica}

Entendemos "tipologia" no sentido tradicional de caracterizar línguas inteiras num estudo comparativo. $\mathrm{Na}$ apresentação descritiva, realizada até agora, descrevemos os diferentes tipos de morfemas e construções. Agora vamos caracterizar línguas e grupos de línguas resumindo os resultados alcançados. Num primeiro passo, vamos estabelecer tipos 
DIETRICH - TIPOLOGIA MORFOSSINTÁTICA DA NEGAÇÃO NAS LÍNGUAS DO ...

de línguas Tupi segundo o número de categorias sintáticas negativas que nelas funcionam. Essas dependem, de modo geral, do número de morfemas negativos que se distinguem. Num segundo passo, a análise tipológica basear-se-á também no tipo de morfemas, no uso de sufixos, prefixos ou outros recursos morfológicos específicos ou, pelo contrário, no uso de morfemas mais independentes, de partículas ou de construções com verbos auxiliares. Desta maneira, vamos opor línguas caracterizadas pelo uso de morfemas negativos diferentes (coesão morfológica) e línguas caracterizadas pela preferência de construções sintagmáticas, pelo uso de partículas independentes que exprimem as diferentes funções negativas, estando reduzido o número de morfemas negativos.

Algumas línguas ficam não-classificáveis por falta de dados. É evidente que a classificação tipológica sempre depende da integridade das informações que temos sobre uma determinada língua. Do quadro seguinte resulta a análise tipológica. Os números da última coluna indicam o número de categorias distinguidas (primeiro número) e o número de morfemas negativos específicos (morfemas descontínuos e sufixos (segundo número). O zero significa: língua não classificável por falta de dados.

Quadro 1: Número de funções negativas

\begin{tabular}{|c|c|c|c|c|c|}
\hline G.cl. & $\mathrm{D} n \ldots i$ & $\mathrm{~L}-\tilde{y}$ & $\mathrm{C}+$ & $\mathrm{P}$-eme & 4 \\
\hline GP. & $\mathrm{D} n \ldots i$ & $\mathrm{~L}-\tilde{y}$ & C- & P ani & $3 / 2$ \\
\hline Avá & $\mathrm{D} n \ldots i$ & $\mathrm{~L}-\tilde{y}$ & C- & $\mathrm{P}$ ani & $3 / 2$ \\
\hline $\mathrm{Kw}$ & $\mathrm{D} n \ldots i$ & $\mathrm{~L}-e \tilde{y}$ & C- & $\mathrm{P}$ ani & $3 / 2$ \\
\hline $\mathrm{Mb}$ & $\mathrm{D} n \ldots i$ & $\mathrm{~L}-e^{‘} \tilde{y}$ & C- & $\mathrm{P}$-eme & 2 \\
\hline Aché & $\mathrm{D}-l l a \tilde{a}$ & $\mathrm{~L}-l l a \tilde{a}$ & C- & $\mathrm{P}$-eme & 3 \\
\hline GO.a. & $\mathrm{D} n \ldots i$ & $\mathrm{~L}-\tilde{a}$ & C- & $\mathrm{P}$-eme & $2 / 1$ \\
\hline GO & $\mathrm{D}-\tilde{a}$ & $\mathrm{~L}-\tilde{a}$ & C- & Paguyje & $2 / 1$ \\
\hline Yuki & D disc. & $\mathrm{L}+$ & $\mathrm{C}+$ & $\mathrm{P}-m e$ & 4 \\
\hline $\mathrm{Si}$ & $\mathrm{D}-\tilde{a}$ & $\mathrm{~L}-\tilde{a}$ & C- & $\mathrm{P} n \tilde{a} \tilde{a}$ & $2 / 1$ \\
\hline Gyu & $\mathrm{D} n \ldots i$ & $\mathrm{~L}-{ }^{\prime} e-\tilde{y}$ & C- & $\mathrm{P}$-eme & 3 \\
\hline War & $\mathrm{D} n \ldots i$ & $\mathrm{~L}-e^{\prime} i$ & $\mathrm{C}+$ & $\mathrm{P}$-eme & 4 \\
\hline Pnã & $\mathrm{D} n \ldots i$ & L-i’tm & C- & $\mathrm{P}$-eme & 3 \\
\hline $\mathrm{Tb}$ & $\mathrm{D} n \ldots i$ & L-e'ym & $\mathrm{C}+$ & $\mathrm{P}$-umê & 4 \\
\hline A-C & $\mathrm{D} n \ldots i$ & $\mathrm{~L} n \ldots i$ & C- & $\mathrm{P}$-eme & 2 \\
\hline AsT & $\mathrm{D} n \ldots i$ & $\mathrm{~L}-e^{\prime} y m$ & $\mathrm{C}-$ & $\mathrm{P}$-eme & 3 \\
\hline Arw & $\mathrm{D} n \ldots i$ & L? & $\mathrm{C}+$ & $\mathrm{P}$-imi & 3 \\
\hline An & D $-x a$ & $\mathrm{~L}-x a$ & C- & $\mathrm{P}-x a$ & $2 / 2$ \\
\hline Sur & $\mathrm{D} n \ldots i$ & $\mathrm{~L}-e^{\prime} \dot{t} m$ & C- & P puhi & $3 / 2$ \\
\hline $\mathrm{Te}$ & $\mathrm{D} n \ldots i$ & L-im & C- & $\mathrm{P} d o$ & 2 \\
\hline $\mathrm{Tp}$ & $\mathrm{D} n \ldots i$ & L-ehým & C- & $\mathrm{P}-e w i$ & 3 \\
\hline AsX & $\mathrm{D} n \ldots i$ & $\mathrm{~L}-e^{\prime} y m$ & C- & $\mathrm{P}-j \tilde{u}$ & 3 \\
\hline SP & D om & L-om & C ? & $\mathrm{P}$ yaba & $2 / 1$ \\
\hline Gav & $\mathrm{D} o o$ & $\mathrm{~L}-o o p$ & C ? & $\mathrm{P} y a ́$ & $3 / 1$ \\
\hline
\end{tabular}

\begin{tabular}{|c|c|c|c|c|c|}
\hline $\mathrm{Kb}$ & $\mathrm{D} n \ldots i$ & L-e'em & $\mathrm{C}+$ & $\mathrm{P}-a w i$ & 4 \\
\hline Kagw & $\mathrm{D} n \ldots i$ & $\mathrm{~L}-e^{\prime} y m$ & $\mathrm{C}+$ & P $n \ldots i$ & 3 \\
\hline $\mathrm{Km}$ & $\mathrm{D} n \ldots i$ & $\mathrm{~L}-e^{\prime} y m$ & $\mathrm{C}+$ & $\mathrm{P}-e m$ & 4 \\
\hline Way & $\mathrm{D} n \ldots i$ & $\mathrm{~L} i(m e)$ & $\mathrm{C}+$ & $\mathrm{P}(-m e)$ & $4 / 3$ \\
\hline Em & $\mathrm{D} n \ldots i$ & $\mathrm{~L} n \ldots i$ & $\mathrm{C}+$ & P mame & $3 / 2$ \\
\hline Zo'ê & $\mathrm{D} n \ldots i$ & $\mathrm{~L} ?$ & $\mathrm{C}+$ & $\mathrm{P} ?$ & $2 / 0$ \\
\hline Guajá & $\mathrm{D} n \ldots i$ & L - $-\tilde{y} m a$ & (C) & $\mathrm{P}$-ате̃ & 3 \\
\hline Ko & D tima & $\mathrm{L}-i m a$ & (C) & $\mathrm{P}$ iná & $3 / 2$ \\
\hline Om & D roa & L-ima & (C) & $\mathrm{P}$ inami & $3 / 1$ \\
\hline $\mathrm{Kp}$ & D -Pim & L -Pim & $\mathrm{C}-$ & P -Pim I & $2 / 1$ \\
\hline $\mathrm{Nh}$ & D $t i-$ & $\mathrm{L} ?$ & $\mathrm{C}-$ & P te- & $2 / 2$ \\
\hline SM & $\mathrm{D} y t . . i$ & $\mathrm{~L} ?$ & $\mathrm{C}+$ & P yt...te & $3 / 2$ \\
\hline $\mathrm{Aw}$ & D d. & $\mathrm{L}-e^{\prime} y m$ & C- & $\mathrm{P}-e t i$ & 3 \\
\hline Kar & D padni & $\mathrm{L}-K i$ & C ? & $\mathrm{P}-y$ & 3 \\
\hline Karo & D i?ke & $\mathrm{L} ?$ & $\mathrm{C}+$ & P yahm. & $3 / 2$ \\
\hline Mek & $\mathrm{D}-a p$ & $\mathrm{~L}-\tilde{a} p$ & $\mathrm{C}-$ & $\mathrm{P}-b \tilde{o}$ & 3 \\
\hline Wró & $\mathrm{D}-\tilde{o m}$ & L- erõm & $\mathrm{C}-$ & $\mathrm{P} ?$ & 2 \\
\hline Jur & $\mathrm{D}-a \tilde{u}$ & $\mathrm{~L}-m \tilde{a}$ & $\mathrm{C}+$ & P máku & $4 / 2$ \\
\hline $\mathrm{Xi}$ & $\mathrm{D}-a \tilde{u}$ & $\mathrm{~L} ?$ & C ? & $\mathrm{P}-a \tilde{u} \mathrm{I}$ & $2 / 1$ \\
\hline Tup & D - 'om & L - 'om & C- & P - 'om I & $2 / 1$ \\
\hline Ak & D -rom & $\mathrm{L} ?$ & C ? & $\mathrm{P} ?$ & $1 / 0$ \\
\hline Mak & D -rom & L -om & C ? & $\mathrm{P} ?$ & $2 / 0$ \\
\hline $\mathrm{Mu}$ & $\mathrm{D} \mathrm{yu}$ & $\mathrm{L}-{ }^{\prime} \tilde{u} m$ & C ? & Р $\eta u$ & 2 \\
\hline
\end{tabular}


6.1. Análise tipológica das funções negativas

Desta primeira análise tipológica resultam quatro tipos de línguas com respeito ao número de funções negativas:

I) Línguas altamente morfológicas (distinção morfológica entre negação declarativa, nominal-lexemática, de constituintes, e de proibitivas): 4 pontos

G.cl., War, Yuki, Tb, LGA, AsX, Kb, Km, Way, Ko, Jur, Karo

Integram-se neste tipo línguas Tupi-Guarani e Tupi. Chama a atenção a posição do Kokama, que, apesar de ter uma origem ainda não conhecida, adotou um grande número de morfemas tradicionais das línguas Tupi-Guarani.

II) Línguas preferentemente morfológicas (distinção reduzida de categorias negativas somente com respeito à negação de constituintes): 3 pontos

GP, Avá, Kw, Mb, Gyu, Si, Nh, Om, AsT, Pnã, Te, Kagw, Tp, Em, Gj, SM, Aw, Kar, Mek Integram-se aqui línguas do subgrupo Maweti-Tupi-Guarani, o Karitiana (Arikém) e o Mekéns (Tupari).

III) Línguas preferentemente sintagmáticas (distinção morfológica entre duas categorias, sendo uma ou duas outras exprimidas mediante partículas, isto é por construções sintagmáticas): 2 pontos

GO, Tapiete, Aché, Si, A-C, Sur, Em, SurP, Gav

Trata-se de um grupo de línguas Tupi-Guarani periféricas e de algumas línguas das subfamílias Tuparí e Mondé.

IV) Línguas altamente sintagmáticas (a distinção entre declarativas, lexemáticas e proibitivas faz-se exclusivamente mediante recursos sintagmáticos; usa-se um único morfema negativo em todos os casos): 1 ponto

$\mathrm{Mu}, \mathrm{Xi}, \mathrm{Tu}, \mathrm{An}, \mathrm{Kp}$

As seguintes línguas não são completamente classificáveis por falta de dados: Zo'ê, Akuntsú, Makuráp; provavelmente isto vale também para o Xipaya.

\subsection{Análise tipológica da coesão morfológica}

Nesta segunda análise tipológica, o foco está na coesão morfológica dos morfemas negativos. A coesão morfológica está marcada no caso do uso de sufixos e morfemas descontínuos, em oposição ao uso de partículas mais ou menos independentes que marca a preferência sintagmática da língua respectiva. Esta preferência pode se interpretar também como tipo analítico, em oposição ao tipo sintético. 
A diferença entre línguas altamente morfológicas ou sintéticas e línguas altamente sintagmáticas ou analíticas na expressão da negação se realiza quando uma categoria negativa se exprime por partículas ou auxiliares negativos. É nas seguintes línguas que a coesão morfológica (síntese) é menor do que a expressão das categorias que sempre se distinguem de uma ou outra maneira:

Guarani paraguaio, Avá-Nhandeva, Kaiowá, Guarani Ocidental, Siriono, SuruiAikewára, Wayãpi, Emerillon, Kokama, Omagua, Ka’apor, Karo, Juruna, Xipaya, Tupari, Surui-Paiter e o Gavião. Deste modo, resulta que as línguas das subfamílias não-TupiGuarani são as que se caracterizam pelo tipo isolante. Têm, em geral, menos sufixos e mais construções sintagmáticas do que as línguas Maweti-Tupi-Guarani, mas também, nestas últimas, há um número considerável de línguas com tendências isolantes.

No Anambé aparece um único sufixo negativo (1 ponto), mas o proibitivo se distingue da declarativa pelo uso do imperativo (mais 1 ponto). Na balança da coesão morfológica pesa também o sufixo ...-i, resto da antiga negação descontínua.

No caso do Wayãpi temos que tomar em consideração a perda do sufixo -me na língua moderna e sua substituição por uma construção sintagmática.

O Zo'ê, o Akuntsú e o Makurap não são classificáveis por falta de dados, embora tenhamos informação sobre duas categorias pelo menos.

\section{Conclusão}

Da descrição das diferentes funções negativas e da morfossintaxe da negação num grande tronco de famílias de línguas como é o tronco Tupi extraimos a seguinte conclusão: a conexão genealógica que existe entre essas famílias linguísticas providencia certa uniformidade morfológica, mas não assegura a conformidade das funções em todos os grupos, nem garante o uso dos mesmos tipos morfossintáticos em cada uma das línguas. Ao contrário, o quadro fica bastante variado, mas os dados reunidos permitem colocar a primeira pedra para estudos diacrônicos, que não é o lugar de iniciar aqui. O que o nosso estudo facilita é a comparação tipológica, não só interna, dentro do Tupi, mas sobretudo a comparação através das línguas do mundo.

Comparando a negação Tupi só com a das línguas Arawak (Michael/Granadillo 2014), Carib e a das línguas europeias, o Tupi, evidentemente, é rico em funções e recursos morfológicos. As línguas Tupi mais ricas distinguem três funções sintáticas de negação, a declarativa, a de constituintes, e as proibitivas, opondo-as a uma ou duas funções de negação nominal-lexemática (privativa e/ou antonímica). A maioria das línguas europeias não tem morfemas diferentes para a negação declarativa e a proibitíva. Só as línguas clássicas (latim, grego) tinham morfemas específicos. Entre as línguas modernas que distinguem as proibitivas das declarativas são o grego moderno, o albanês e o húngaro. A negação das declarativas manifesta-se mediante partículas negativas, antepostas ao verbo em algumas línguas (cf. vasco $\boldsymbol{e} \boldsymbol{z}$ dakit 'eu não sei', como em português), pospostas em outras (cf. alemão er kam nicht 'ele não veio'). O francês culto e as línguas célticas (galês, bretão) conhecem morfemas descontínuos (por exemplo, francês il n'est pas venu). Em turco se observa o infixo -mi-/-mu(gel-mi-yor-um vir-NEG-PRES-1s. 'eu não venho'). O finlandês e o inglês usam auxiliares negativos, em declarativas e em proibitivas. Esta estratégia morfossintática se conhece também em línguas amazônicas, entre elas línguas do tronco Tupi (exemplos 05, do Gavião, e 39, do Karo, acima). Finalmente, a negação lexemática, uma categoria bem desenvolvida da derivação Tupi, está ao nível de línguas como o inglês e o português. 
Nas línguas da família Carib, a marca da negação declarativa é diferente da proibitiva. Usam-se sufixos e partículas independentes. Em Panare (Carib; Payne/Payne 2013: 368-371) observamos uma morfologia peculiar: o morfema descontínuo $k(a) \ldots$ e(me) apresenta o mesmo elemento -eme que carateriza algumas línguas TG (cf. $\S 5.2 .3$ acima). Na maioria das línguas Arawak (Michael/Granadillo 2014) encontramos partículas independentes para negar orações declarativas, só o Tariana usa um morfema descontínuo ( $m a$... káde no não-futuro, ma ... kásu para o futuro; Michael/Granadillo 2014: 90-95). As proibitivas formam-se com partículas específicas ou, pelo menos em Garífuna, Lokono e Kurripako, com um morfema descontínuo ( $m a$ - e um sufixo). O prefixo negativo maaparece em muitas línguas Arawak para formar negações lexemáticas privativas. Não se acham, porém, nas duas famílias sul-americanas, morfemas específicos para a negação de constituintes, comparáveis aos das línguas Tupi. Este não é o lugar para continuar a pesquisa tipológica-comparativa, que seria um estudo diferente. O Tupi distingue-se pela já mencionada riqueza de funções negativas.

\section{$\overline{\text { Referências }}$}

Aragon, Carolina Coelho (2014). A grammar of Akuntsú: a Tupian language (Ph.D. dissertation). Honolulu: University of Hawai'i at Mānoa.

Betts, LaVera (2012). Kagwahiva dictionary. Anápolis, GO: SIL

Bontkes, Carolyn (1985). Subordinate Clauses in Surui. Porto Velho Workpapers. SIL.

Bontkes, Willem; Bontkes, Carolyn (2009). Phonemic analysis of Surui. Anápolis, GO: SIL

Borges, Mônica Veloso (2006). Aspectos fonológicos e morfossintáticos da língua Avá-Canoeiro (Tupi-Guarani) (Tese de doutorado). Campinas: UNICAMP.

Boudin, Max H. (1978). Dicionário de tupi moderno (Dialeto tembé ténêtéhara do alto do rio Gurupi). 2 vols. (Col. Ciências Humanas.). São Paulo: Secretaria da Cultura, Ciência e Tecnologia.

Braga, Alzerinda de Oliveira (2005). Aspects morphosyntaxiques de la langue Makurap/Tupi (Thèse de doctorat). Toulouse: Université de Toulouse-le-Mirail.

Cabral, Ana Suelly Arruda Câmara; Dall'Igna Rodrigues, Aryon (2003). Dicionário Asurini do TocantinsPortuguês. Belém: UFPA.

Canese, Natalia Krivoshein de; Acosta Alcaraz, Feliciano (2001). Gramática guaraní (Colección Ñemitỹ). Asunción: Universidad Nacional de Asunción.

Cardoso, Valéria Faria (2008). Aspectos morfossintáticos da língua Kaiowá (Guarani) (Tese de Doutorado em Linguística). Campinas: UNICAMP.

Carneiro, Denize de Souza (2012). Construções negativas em Sateré-Mawé (Dissertação de mestrado em Linguística). Uberlândia: UFUb.

Copin, François (2012). Grammaire du wayampi (tupi-guarani) (Thèse de doctorat). Paris: Université Denis Diderot - Université de Paris 7. 
Corrado, Alejandro María (1896). Reglas elementares de la lengua chiriguana ... Obra pòstuma del R. P. Alejandro Maria Corrado ... revisada, corregida y dada a luz por el R. P. Dorotèo Giannecchini. Lucca: Tipografia Arciv. S. Paolino.

Couto e Silva, Ariel Pheula (2015). Elementos de fonologia, morfossintaxe e sintaxe da língua Avá-Canoeiro do Tocantins (Dissertação de mestrado em Linguística). Brasília: UnB.

Crofts, Marjorie (2004). Aspectos da língua munduruku. Cuiabá, MT: SIL.

Cruz, Aline da (2011). Fonologia e gramática do Nheengatú. A língua geral falada pelos povos Baré, Warekena e Baniwa. Utrecht: LOT.

Dietrich, Wolf (1986). El idioma chiriguano. Gramática, textos, voccabulario. Madrid: ICI.

Dietrich, Wolf (2003). Formas de la negación en las lenguas tupí-guaraníes de Bolivia. Thule (Perugia) 14/15: 233-250.

Dietrich, Wolf (2014). O conceito de 'Língua Geral' à luz dos dicionários de língua geral existentes. D.E.L.T.A, vol. 30, número especial, pp. 591-622.

Dooley, Robert A. (2006). Léxico guarani: Dialeto mbyá. Introdução, esboço gramatical, léxico. Cuiabá, MT: SIL.

Drude, Sebastian (2008). Tense, Aspect and Mood in Aweti verb-paradigms: Analytic and synthetic forms. In David K. Harrison; David S. Rood; Arienne Dwyer (eds.). Lessons from Documented Endangered Languages, pp. 67-110. Amsterdam, Philadelphia: John Benjamins.

Everett, Caleb (2006). Patterns in Karitiana: Articulation, Perception, and Grammar (Ph.D. dissertation). Houston, Texas: Rice University.

Fargetti, Cristina Martins (2007). Estudo fonológico e morfossintático da língua Juruna. Munich: Lincom Europa.

Gabas, Jr., Nilson (1999). A grammar of Karo, Tupi (Brazil) (Ph.D. dissertation). Santa Barbara: University of California, Santa Barbara.

Galucio, Ana Vilacy (2001). The morphosyntax of Mekens (Tupi) (Ph.D. dissertation). Chicago: University of Chicago.

Gomes, Dioney Moreira (2006). Estudo morfológico e sintático da língua Mundurukú (Tupí) (Tese de doutorado em Linguística). Brasília: UnB.

González, Hebe Alicia (2005). A grammar of Tapiete (Tupi-Guarani) (Ph.D. dissertation). Pittsburgh: University of Pittsburgh.

Grenand, Françoise (1980). La langue wayãpi (Guyane Française). Phonologie et grammaire. Paris: SELAF.

Hoeller, P. Fray Alfredo, O.F.M. (1932). Grammatik der Guarayo-Sprache. Guarayos - Hall (Tirol): Verlag der Missionsprokura der P.P. Franziskaner.

Jensen, Allen A. (1994). Wayampi. In Kahrel, Peter \& Rene van den Berg (eds.). Typological studies in Negation, pp. 343-364. Amsterdam, Philadelphia: John Benjamins.

Kakumasu, James (1986). Urubu-Kaapor. In Derbyshire, Desmond C.; Pullum, Geoffrey K. (eds.). Handbook of Amazonian Languages, vol. I, pp. 326-403. Berlin-New York, Amsterdam: Mouton de Gruyter. 
León de Santiago, Pedro (1791[2005]). Alguna noticia de la gramática chiriguana. Edición preparada por Iván Nasini y Elio Ortiz. Italian Journal of Linguistics 17(2): 373-414.

Lopes, Jorge Domingues (2014). Uma interface da documentação linguística e modelos lexicográficos para línguas indigenas brasileiras. Uma proposta para o Surui-Aikewára. (Tese de doutorado em Linguística). Brasília: UnB.

Magalhães, Marina Maria Silva (2007). Sobre a morfologia e a sintaxe da língua Guajá (Família Tupi-Guarani) (Tese de doutorado em Linguística). Brasília: UnB.

Michael, Lev; Granadillo, Tania (eds.) (2014). Negation in Arawak Languages. Leiden, Boston: Brill.

Miestamo, Matti (2008). Standard negation. The negation of declarative verbal main clauses in a typological perspective. Berlin, Boston: De Gruyter Mouton.

Monserrat, Ruth Maria Fonini (2012). A negação em Aweti. Revista Brasileira de Linguística Antropológica 4(1): 29-39.

Moore, Denny (2002). Verbos sem flexão. In Rodrigues, Aryon Dall'Igna; Cabral, Ana Suelly Arruda Câmara (eds.). Atas do I Encontro Internacional do Grupo de Trabalho sobre línguas indigenas da ANPOLL, pp. 139-150. Belém: EDUFPA.

Moore, Denny (2012). Relative clauses in Gavião of Rondônia. In Comrie, Bernard; Estrada-Fernández, Zarina (eds.). Relative Clauses in Languages of the Americas, pp. 243-252.Amsterdam, Philadelphia: John Benjamins.

O'Hagan, Zachary (2011). Proto-Omagua-Kokama: Grammatical sketch and prehistory (Master Thesis) Berkeley: University of California.

Payne, Thomas E.; Payne, Doris L. (2013). A typological grammar of Panare. A Cariban Language of Venezuela. Leiden, Boston: Brill.

Pereira, Antônia Alves (2009). Estudo morfossintático do Asurini do Xingu (Tese de doutorado em Linguística). Campinas: UNICAMP.

Praça, Walkíria Neiva (2007). Morfossintaxe da língua Tapirapé (Familia Tupi-Guaraní) (Tese de doutorado em Linguística). Brasília: Universidade de Brasília.

Ramirez, Henri; França, Maria Cristina Victorino de (2017). O Warázu (Tupi-Guarani) do Guaporé: primeira descrição linguística. LIAMES 17 (edição especial).

Reis Rodrigues, Carmen Lúcia (1995). Etude morphosyntaxique de la langue Xipaya (Brésil) (Thèse de doctorat). Université Denis Diderot (Paris VII).

Restivo, Pablo (1724 [1996]). Arte de la lengua guaraní. Presentación, transcripción: Silvio M. Liuzzi. Ed. en ligne: Jean-Michel Hoppan, avec la collaboration de Marc Thouvenot. CELIA. Disponível em: http://celia.cnrs.fr/FichExt/Paleographies/Guarani/Guarani_intro.htm (Acesso 06/03/2017).

Rose, Françoise (2011). Grammaire de l'èmérillon teko, une langue tupi-guarani de Guyane Française. Leuven, Paris, Walpole, MA: Peeters.

Rößler, Eva-Maria (2008). Aspectos da gramática Achê: descrição e reflexão sobre uma hipótese de contato (Dissertação de mestrado em Linguística). Campinas: UNICAMP.

Rößler, Eva-Maria (2015). Inflectional morphology restructuring in aché - discussing grammatical change and language contact in tupi-guarani subgroup -1, BMPEG-CH 10(2):371-393: http://dx.doi.org/10.1590/198181222015000200009 
DIETRICH - TIPOLOGIA MORFOSSINTÁTICA DA NEGAÇÃO NAS LÍNGUAS DO ...

Schermair, P. Fr. Anselmo (1949). Gramática de la lengua sirionó. La Paz: Gráfica de A. Gamarra.

Seki, Lucy (2000). Gramática do Kamaiurá: Língua tupi-guarani do Alto Xingu. Campinas: Editora da Unicamp - São Paulo: Imprensa Oficial.

Solano, Eliete de Jesus Bararuá (2009). Descrição gramatical da língua Araweté (Tese de doutorado em Linguística). Brasilia: UnB.

Souza e Silva, Auristéa Caetana (1999). Aspectos da referência alternada em Parakanã (Dissertação de mestrado em Linguística). Belém: UFPA.

Vallejos Yopán, Rosa (2010). A grammar of Kokama-Kokamilla (Ph. D. dissertation). Eugene: University of Oregon.

Villafañe, Lucrecia (2004). Gramática Yuki, lengua Tupi-Guarani de Bolivia (Ph.D. dissertation). Nijmegen: Radboud Universiteit; Tucumán: Universidad Nacional de Tucumán.

Weiss, Helga E. (comp.) (2005). Dicionário Kayabi-Português com um glossário Português-Kayabi. Brasília: SIL.

\section{Abreviaturas}

$3 c$

A-C

Ak

An

AsT

AsX

ATR

AUX

Avá

Aw

CAS

CAUS

CAUS.COM

CIRC

CL.RD

COL

CONT

COP

DAT

DEM

DESID

DIF

DIR

DUR

Em

EV terceira pessoa co-referencial

Avá-Canoeiro

Akuntsú

Anambé

Asurini do Tocantins

Asurini do Xingú

atributivo (nominalizador que forma atributos)

auxiliar

Avá-Nhandeva, Avá-Guarani

Awetí

caso argumentativo

causativo

causativo-comitativo

complemento circunstancial

clasificador redondo

coletivo

ação contínua

cópula negativa

dativo

demonstrativo

desiderativo

locativo difuso

direção

durativo

Emérillon

evidencialidade 


\begin{tabular}{|c|c|}
\hline FIN & finalidade \\
\hline FOC & focalizador \\
\hline FRUST & frustrativo \\
\hline FUT & futuro \\
\hline Gav & Gavião \\
\hline G.cl. & Guarani clássico \\
\hline GENR & genérico \\
\hline GER & gerúndio \\
\hline $\mathrm{Gj}$ & Guajá \\
\hline GO & Guarani Ocidental, chiriguano \\
\hline GO.a & Guarani Ocidental antigo \\
\hline GP & Guarani paraguaio \\
\hline Gyu & Guarayu \\
\hline HORT & hortativo \\
\hline IMP & imperativo \\
\hline IMPERF & imperfectivo \\
\hline IND & indefinido \\
\hline IND1 & indicativo 1 \\
\hline INDET & pessoa indeterminada \\
\hline INJ & injuntivo \\
\hline INT & intensificador \\
\hline INTR & interrogação \\
\hline IRR & modo irreal \\
\hline Jur & Juruna \\
\hline Kar & Karitiana \\
\hline $\mathrm{Kb}$ & Kayabí \\
\hline $\mathrm{Km}$ & Kamayurá, Kamaiurá \\
\hline Ko & Kokama \\
\hline Mek & Mekéns \\
\hline MOD & modalizador \\
\hline Kagw & Kagwahiw(a) \\
\hline Kp & Ka'apor \\
\hline Kw & Kaiowá \\
\hline LGA & Língua Geral Amazônica \\
\hline $\mathrm{Mb}$ & Mbyá \\
\hline MS & masculino \\
\hline $\mathrm{Mu}$ & Mundurukú \\
\hline NEG & negação \\
\hline $\mathrm{Nh}$ & Nheengatu \\
\hline NM & (marca pessoal) nominal \\
\hline NOM & nominalizador \\
\hline OBJ & objeto direto \\
\hline OBR & obrigacional \\
\hline Om & Omagua \\
\hline PAS & passado \\
\hline
\end{tabular}


DIETRICH - TIPOLOGIA MORFOSSINTÁTICA DA NEGAÇÃO NAS LÍNGUAS DO ...

\begin{tabular}{|c|c|}
\hline PERF & aspecto perfectivo \\
\hline $\mathrm{pl}$ & plural \\
\hline Pnã & Parakanã \\
\hline POS & possessivo \\
\hline POT & potencial \\
\hline PRON & pronome pessoal \\
\hline PROX & proximidade \\
\hline PTG & Proto-Tupí-Guarani \\
\hline RED & reduplicação \\
\hline REF & sufixo de referência \\
\hline REFL & reflexivo \\
\hline REL & flexão relacional \\
\hline rem & passado remoto \\
\hline RESTR & restritivo \\
\hline $\mathrm{s}$ & singular \\
\hline $\mathrm{Si}$ & Siriono \\
\hline SIMIL & similitivo \\
\hline SUBJ & subjuntivo \\
\hline SUBORD & subordinador \\
\hline SUJ & sujeto \\
\hline Sur & Surui-Aikewára \\
\hline SurP & Surui-Paiter \\
\hline $\mathrm{Tb}$ & Tupinambá \\
\hline $\mathrm{Te}$ & Tembé \\
\hline TEM & vogal temática \\
\hline $\mathrm{TG}$ & Tupí-Guarani \\
\hline $\mathrm{Tp}$ & Tapirapé \\
\hline VBLR & verbalizador \\
\hline War & Warázu, Guarasu-Pauserna \\
\hline Way & Wayãpi \\
\hline $\mathrm{Xi}$ & Xipaya \\
\hline
\end{tabular}

Recebido: 23/11/2016

Versão revista e corrigida: 7/3/2017

Aceito: 12/3/2017. 